\title{
Ecoturismo e (Des)Educação Ambiental
}

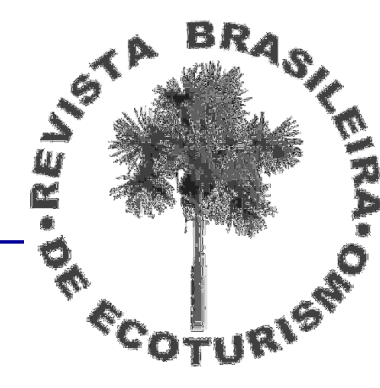

\author{
Euler Sandeville Júnior, Flávia Tiemi Suguimoto
}

\section{RESUMO}

Este trabalho decorre de observações em locais de ecoturismo (no interior do Estado de São Paulo) e de discussões anteriores dos autores sobre a forma de se pensar e se fazer o turismo na natureza. Essas pesquisas, juntamente com uma bibliografia atual sobre o tema, permitem questionar se os formatos padronizados no segmento podem ainda favorecer, ou em que medida, a formação de uma consciência ambiental. Ou seja, o ecoturismo, como se constitui, não estará contribuindo para uma idéia fantasiosa de consciência ambiental? O contato com a natureza é um grande estímulo à sensibilização sobre o ambiente e à sua conservação, mas existe um espaço a preencher entre essa sensibilização e a Educação Ambiental. O grande desafio se encontra em conseguir transformar essa sensibilização em educação e, consequentemente, em ações afetivas e efetivas. No entanto, a relação entre Educação Ambiental e o ecoturismo, que seria esperada como integrante desse segmento se aceitarmos as diversas definições e entendimentos para essa atividade, na prática, tem apresentado problemas que comprometem o próprio alcance da idéia de ecoturismo. Essas dificuldades têm sido apontadas tanto no âmbito acadêmico quanto no empresarial. Existem estudos recentes que identificam esse problema e procuram construir uma interpretação. Trazer os impasses à discussão é o grande mérito desses trabalhos, contribuindo para desmistificar a atividade. $O$ entendimento da questão, contudo, deverá relacionar os problemas já apontados com quadros sociais nos quais se constituem. A questão tem sido reduzida a uma crítica (necessária) da espetacularização da sociedade de consumo, ou creditada a uma deficiência de conhecimento técnico e de falta de capacitação do setor para lidar adequadamente com essa integração entre ecoturismo e Educação Ambiental (o que certamente ocorre). A dificuldade, entretanto, não pode ser creditada apenas ao ecoturismo, e ao comportamento do turista ou do empresário, e nem mesmo aos impasses nas práticas de Educação Ambiental (estes não têm sido considerados nos trabalhos que consultamos). $O$ arcabouço das práticas e suas referências empíricas e teóricas precisa ser trazido para a discussão da realidade social em que se dão, inclusive em seus aspectos estruturais, culturais e afetivos, o que poderá mostrar contradições importantes e mais profundas do que aquelas já indicadas acima. A não percepção dessas relações gera reducionismos que condenarão as soluções apresentadas a apenas renovar as dificuldades e a não colocar plenamente em cheque as suas causas.

PALAVRAS-CHAVE: Ecoturismo, Educação Ambiental, Consciência Ambiental 


\section{Ecotourism and (un)Environmental Education}

\section{ABSTRACT}

This paper stems from observations in the local ecotourism (within the State of Sao Paulo) and previous discussions of the authors on how to think and create tourism in the nature. These findings, together with a current bibliography on the topic, allow us to question whether the standard formats in the segment can still improve, and if so, to what extent, the formation of an environmental awareness. In other words, will ecotourism, as it is, not be contributing to an unrealistic idea of environmental consciousness? Contact with nature is a great stimulus to raise awareness about the environment and its conservation, but there is a space to fill between this awareness and environmental education. The challenge lies in achieving this change from awareness to education and, therefore, into affective and effective actions. However, the relationship between environmental education and ecotourism, which would be expected to be part of this segment if we accept the various definitions and understandings for this activity, in practice, has presented problems that compromise the very scope of the idea of ecotourism. These difficulties have been identified both by the academic body and the business people. Recent studies identify this problem and try to build an interpretation. Bringing the issue to be widely discussed is the great merit of this research, helping to demystify the activity. The understanding of the issue, however, should relate the problems which have been already discussed within their social contexts. The issue has been reduced to a (necessary) criticism of the ostentation of the consumer society, or credited to a deficiency of technical knowledge and lack of training in the industry to adequately deal with the integration of ecotourism and environmental education (what certainly occurs). The difficulty, however, cannot be credited only to ecotourism, neither the behavior of the tourist or businessman, not even to the difficulties in the practice of environmental education (they have not been considered in the research we consulted). The framework of practices and their theoretical and empirical references must be brought to the discussion of social reality where they lie, including their structural, cultural and emotional aspects, which may show deeper and more important inconsistencies than those already mentioned above. The non-perception of these relationships creates a reductionism that condemns the solutions presented as to only being able to renew the difficulties and not to fully investigate their causes.

KEYWORDS: Ecotourism, Environmental Education, Environmental Consciousness

O presente trabalho é fruto de observações realizadas em alguns destinos de Ecoturismo ${ }^{1}$, em especial na cidade de Itararé, localizada o interior do Estado de São Paulo e bastante freqüentada por pessoas que buscam essa modalidade e o turismo de aventura. Decorre também de discussões e observações sobre a forma de se pensar e se fazer o turismo na natureza (SUGUIMOTO, 2007; SANDEVILLE JR., SUGUIMOTO, 2008) e que, acredita-se, devem ser ainda pensadas e discutidas para avanços na área. 
O empreendimento de Ecoturismo em Itararé está localizado em uma fazenda ${ }^{2}$, com muitos atrativos naturais e seu público alvo são famílias e jovens, que vão em busca, principalmente, do turismo de aventura. Um pequeno fato ocorrido pode ajudar na discussão que se apresenta. Observou-se, juntamente com um grupo de pessoas, comandadas por um guia local, uma criança que virou-se para sua mãe e disse que naquele local não se podia jogar papel no chão, pois "prejudicaria a natureza". Muitas pessoas presentes não se mostraram interessadas nas explicações do guia, algumas disseram "que não queriam ter aula, pois estavam de férias". Houve comentários que demonstraram algum tipo de resistência ao formato padrão que muitos empreendimentos desse segmento costumam realizar, que é a visitação guiada, com o intuito de desenvolver Educação Ambiental. Essa dificuldade tem sido observada também na literatura especializada, mas acredita-se que é necessário avançar na discussão de suas possíveis causas.

O comentário da criança, a afirmativa de sua mãe e todos os outros comentários e comportamentos dos (eco?) turistas nos fazem pensar no papel da atividade como possibilidade para Educação Ambiental, em sua real eficiência, no modo como vem sendo praticada. $O$ Ecoturismo é o segmento turístico de maior crescimento no Brasil, segundo o Ministério do Turismo (BRASIL, 1994). A ABETA (Associação Brasileira das Empresas de Ecoturismo e Turismo de Aventura) conta atualmente com 216 empresas associadas e afirmou que o segmento apresentou lucro nacional de $\mathrm{R} \$ 490$ milhões em $2008^{3}$, com perceptível crescimento da oferta de destinações de Ecoturismo. Durante o $4^{\circ}$ Salão de Turismo, realizado em julho de 2009, das 1,7 mil pessoas entrevistadas, $34,3 \%$ apontaram o Ecoturismo e o Turismo de Aventura como próximos destinos, ficando atrás apenas do Turismo de Sol e Praia, com 52,1\% ${ }^{4}$.

O Ecoturismo, segundo as Diretrizes para a Política Nacional de Ecoturismo é:

Um segmento da atividade turística que utiliza de forma sustentável o patrimônio natural e cultural, incentiva sua conservação e busca a formação de uma consciência ambientalista através da interpretação do ambiente, promovendo o bem estar das populações envolvidas (BRASIL, 1994).

Segundo os preceitos do Ecoturismo, é através da Educação Ambiental, favorecida pelo contato das pessoas com os lugares de natureza, que pode-se despertar uma consciência ambiental de conservação dos locais. Essa seria a base do Ecoturismo ser uma atividade de sustentabilidade para os locais que a desenvolvem. Porém, no caso observado, que certamente não é isolado, não foi possível perceber nenhum avanço sobre o despertar de uma consciência ambientalista dos turistas, além de nenhum grande esforço por parte empreendimento. Acredita-se que é importante questionar se esses formatos estão favorecendo uma conscientização, ou em que medida, e se a Educação Ambiental nesses moldes, não está levando a uma idéia fantasiosa 
de consciência ambiental. Esse não é o único exemplo de tentativas mal sucedidas de Educação Ambiental nos locais de Ecoturismo, e isso só vem a contribuir para que se pense no real objetivo dos prestadores de serviços de Ecoturismo. Será mesmo o Ecoturismo uma alternativa ao turismo convencional?

Concorda-se que o contato com a natureza é um grande estímulo à sensibilização sobre o ambiente e à sua conservação, mas existe um espaço a preencher entre essa sensibilização e a Educação Ambiental. Neiman (2007, p.18) afirma que, se o contato com a natureza for proporcionado de forma adequada, estimulando todos os sentidos (sentir o cheiro da mata, olhar os animais, ouvir os barulhos), há uma melhora de sentimentos positivos em relação ao que deve ser conservado, afinal "não é apenas através do sentimento ético de obrigação que se pode trabalhar o gosto pela natureza e pela conservação".

O grande desafio se encontra em conseguir transformar essa sensibilização em educação e, consequentemente, em ações afetivas e efetivas. Por falta de conhecimento e pela necessidade de geração de lucros, que decorre da boa aceitação do cliente, as empresas de Ecoturismo não sabem como inserir Educação Ambiental em meio a atividades de lazer e turismo. Esta dificuldade, em parte, é consequência de uma contradição mais ou menos velada, ou pouco explicitada, entre a oferta que se apresenta e o caráter convencional que padroniza a percepção em função do produto, mesmo que não se dê conta, perde-se assim a possibilidade de uma dimensão essencial de trabalho educativo.

Em estudo desenvolvido por Hintze (2008) com algumas operadoras de Ecoturismo, o autor afirma que as empresas não estão qualificadas e nem sabem como desenvolver programas de Educação Ambiental. Hintze analisa o Ecoturismo como segmento alternativo ao turismo convencional, buscando entender quais aspectos diferenciam uma atividade da outra e se o Ecoturismo pode realmente ser uma possibilidade de Educação Ambiental. Através de entrevistas com operadoras de Ecoturismo e com pesquisadores do tema, o autor defende a necessidade de integração entre academia e mercado e conclui que o Ecoturismo, como atividade de mercado, produz "uma subjetividade consumista nos participantes do processo" (HINTZE, 2008, p.13) , o que torna o Ecoturismo uma "atividade pouco utilizada para a disseminação para uma consciência ambientalista" (idem). Discorda-se dessa associação de Hintze entre a academia e o mercado como base para a solução dos dilemas de um ou de outro, dada a natureza própria dessas atividades, que necessita ser entendida. No entanto, o autor parece ter razão em sua restrição à atual formado Ecoturismo, pois sua caracterização, essencialmente como negócio, está se impondo sobre os aspectos constitutivos alegados para a atividade.

É pertinente o alerta de vários autores, que rompe o acordo de uma aceitação frágil entre consumo, prestação de serviços e produção de conhecimento. Neiman (2007, p.172) numa direção próxima da que se aponta, observa que por ter o Ecoturismo transformado as viagens à natureza em um negócio, o que ele produz são viagens e não experiência e nem conhecimento, "só reproduz experiências de marketing 
e conceitos administrativos convencionais, aplicados tradicionalmente a outras áreas do conhecimento humano".

A experiência é um dos pontos fundamentais quando se fala em turismo ou em Ecoturismo, e acredita-se que a sua redução a exterioridades em função das exigências do consumo de massa, estabelecem níveis de controle sobre o olhar do turista (SANDEVILLE JR., SUGUIMOTO, 2008). Urry (2001, p.16) acredita que a atividade turística é capaz de controlar a percepção do turista, pois "existem profissionais qualificados que ajudam a construir e desenvolver nosso olhar enquanto turistas" e também afirma que nesses lugares turísticos, as pessoas já vão com conceitos preestabelecidos.

Estabelecer laços afetivos com os lugares e com a paisagem é fundamental para dotá-los de sentido. É através da afetividade que as pessoas terão consciência da conservação dos lugares, porém, só se estabelece afetividade e vínculo com aquilo que se conhece. O estabelecimento de uma afetividade superficial decorrente da transformação dos lugares em produtos, talvez seja um dos obstáculos que faz com que o Ecoturismo não consiga aliar, de forma eficaz, a Educação Ambiental às suas atividades. O problema, não estaria assim, apenas na deficiência do conhecimento técnico e conceitual das operadoras, embora isso seja evidente e exagerado em muitos casos, mas reside na natureza mesma da atividade econômica.

Afetividade não se estabelece prontamente, ela é fruto de vivência, que muitas vezes os programas de Ecoturismo inviabilizam, quando substituem o conhecimento e a troca efetiva por um cenário controlado e destinado ao mercado. Assim, essa contradição intrínseca entre afetividade e o discurso que a sustenta é agravado pelas dificuldades de conceber um processo educativo subordinado às exigências tão tênues com a natureza e a cultura de que as empresas se valem, representando um "complicador", um custo necessário da atividade e incapaz de organizá-la criativamente, tal como nos casos observados.

Esta poderia ser uma das causas pelas quais Hintze (2008, p. 79$)$ afirma, através das entrevistas com as operadoras de Ecoturismo, que elas se encontram desconfortáveis em aliar turismo e educação, "alegando que a inserção de discursos ambientalistas é fator de desgaste do produto, pois o momento de lazer proposto pela prática do Ecoturismo não combina com tal postura. Seria uma forma de se perder clientes".

Não deixa de surpreender, entretanto, uma alegação como essa, que empresas que atuam no setor de Ecoturismo, podendo indicar que já se ultrapassou, em muito, o primeiro momento de transformação da natureza em produto turístico, e que já se vive um refluxo, um desgaste devido à contradição que esses produtos engendram. Apresenta-se um desafio ao Ecoturismo. Para os discursos superficiais, o Ecoturismo é uma grande ferramenta para a Educação Ambiental, mas comprova-se na prática, que a realidade que se apresenta em um número expressivo de casos é outra. 
Outro indicador da falta de preparo e interesse no desenvolvimento da educação através do Ecoturismo e da preocupação das empresas com o negócio turismo pode ser observado no site da $\mathrm{ABETA}^{5}$. A associação das empresas de Ecoturismo e turismo de aventura apresenta como "Projetos e Ações" um programa de promoção e comercialização internacional dos destinos brasileiros de Ecoturismo, onde todas as ações são voltadas a estratégias de aumento de vendas, não demonstrando preocupação com Educação Ambiental ou conservação dos lugares a serem comercializados. Fica claro, portanto, que as operadoras entrevistadas por Hintze ultrapassam o exemplo das operadoras anunciando a postura de todo o trade do Ecoturismo, no que diz respeito à Educação Ambiental.

Voltando à descrição dos comportamentos dos turistas, e da fala da criança de que naquele local não era permitido jogar papel no chão, além da reação dos outros participantes, deve-se pensar que o problema seja de ordem social e não simplesmente de estratégias de venda. A convergência atual entre consumidor (turista) e prestadores de serviços (da organização ao destino) apresenta fragilidades que são agravadas pela incorporação superficial de comportamentos de controle que se introjetam, mas que atuam no nível das exterioridades.

Educação, em um sentido amplo, significa um processo contínuo de ações conjuntas e nunca de fatores isolados. Segundo Morin (2000, apud HINTZE, 2008) a educação não deve limitar-se aos bancos escolares de um sistema formal, pois:

A educação em seu amplo significado tem como missão dedicar-se à identificação da origem de erros, ilusões e cegueiras, e com isso, armar cada um, para o combate vital para a lucidez; realizar o exame e o estudo da complexidade humana; e ensinar a ética da compreensão planetária, através de uma reforma em sua mentalidade (MORIN, 2000, apud HINTZE, 2008, p.66)

A Educação Ambiental é uma das diversas formas de educação não-formal ${ }^{7}$ que pode oferecer aos indivíduos a oportunidade de uma consciência maior sobre seu papel enquanto cidadão, de conservação de seu habitat. Porém, tornar uma pessoa sensível ao ambiente não é algo que se ensine de forma fácil, talvez estimular seria a forma correta, já que não se trata de uma nova condicionante, mas de um desenvolvimento, aprendizagem no seu sentido mais rico, que deve incluir a descoberta e a possibilidade de transformação. Para isso, demanda-se tempo e remete-se, portanto, a questão para uma esfera além das exterioridades e suas conveniências, e para além do alcance do mercado, no âmbito da consciência da ação social e de sua capacidade ativa transformadora, a qual está, como se percebe, bastante além do momento em que se constrói tanto a oferta quanto o consumo. Ou também, vendo de outra forma, a realidade de mercado está aquém da aspiração humana que se quer ver aflorar. 
O dinheiro e a troca no mercado põem um véu, mascaram as relações sociais entre as coisas, fazendo-as parecer relações entre pessoas. Essa ilusória transparência torna opacas as relações entre os consumidores e aqueles que produziram as mercadorias que são consumidas. Nas relações de compra e venda no mercado, os consumidores não reconhecem nenhum afeto por quaisquer sofrimentos, privações, dramas pessoais dos indivíduos que produziram tais mercadorias. É apenas com a mercadoria (e com o dinheiro pago por ela) que se dá a única relação (HINTZE. 2008, p. 41).

Acredita-se que estar e ser sensível a algo é conseqüência de vivências que se estabelecem durante algum tempo. Seja com pessoas ou com lugares, o tempo tornase fator fundamental para que se criem laços afetivos, e que pode ser um dos fatores que dificulta qualquer trabalho de Educação Ambiental através do Ecoturismo. Nessas condições, as aspirações do Ecoturismo, tal como definido nos textos que o conceituam e o propõem, ficam seriamente comprometidas, não se diferenciando de outra forma de turismo, senão pelo cenário. Nesse contexto, a Educação Ambiental, acaba tendo pouco de educação, confundindo-se com recreação, distração, ocupação do tempo livre.

Normalmente, o tempo de permanência nos lugares de visitação não é tão extenso a ponto de tornar o turista sensível àquela realidade, e até mesmo a forma como essa realidade é vivenciada de forma controlada e espetacularizada a torna opaca. O turismo, enquanto mercadoria se traveste de outra imagem, como a do paraíso, da fantasia, do sonho, principalmente porque não é objeto palpável, que se compra e leva para casa, mas sua real intenção de lucro acaba por traí-lo e evidenciar os limites da mercadoria, para um público já pouco exigente, senão de distração.

Um fato que pode ser determinante na eficácia de programas de Educação Ambiental poderia ser o incentivo à valorização dos lugares do cotidiano das pessoas. Essa valorização nem sempre ocorre nos locais de visitação turística, devido aos diversos fatores já expostos, mas talvez possa ser estendida a esses locais, a partir do momento que as pessoas aprendem a valorizar, a compreender criticamente e a atuar positivamente na transformação dos lugares onde vivem. A complexidade para se instrumentalizar esse tipo de conduta, sem cair na mesma condição que aqui se questiona, deve ser evidente ao leitor, mas merece sua colocação.

Os laços de afetividade das pessoas com os lugares acontecem porque há uma história, houve acontecimentos, experiências que os tornaram especiais. Normalmente esses locais são os lugares onde se vive, onde se passou uma parte da vida, onde houve um acontecimento importante, enfim, geralmente são locais que pertencem ou pertenceram durante um tempo ao cotidiano das pessoas. É preciso valorizar esses locais, pois são eles que ajudam a contar a história de vida dessas pessoas. Se não se valoriza esses locais que pertencem ao cotidiano, como valorizar lugares, num primeiro momento, estranhos? No entanto, o que atrai os visitantes no turismo são 
distensões, momentos que têm seu valor, mas são insuficientes para contribuir para uma consciência ambiental, que se constrói nas práticas do cotidiano.

A Educação Ambiental é realmente facilitada pelos ambientes naturais, porque a idéia de natureza pode causar nas pessoas uma maior sensibilidade. Porém, acredita-se que se as pessoas não conseguem valorizar e serem sensíveis aos ambientes de seu cotidiano, essa Educação Ambiental proposta em outros locais torna-se desconexa da realidade, fantasiosa. Pensar que não se pode jogar o lixo no chão porque se está em um lugar de natureza, ou que a consciência ambiental resida na atitude ocasional, diferenciando esse lugar de natureza do lugar de seu cotidiano torna-se leviano.

$\mathrm{Na}$ verdade, avançando nesse argumento, seria importante se estabelecer uma consciência do modo como são produzidos os lugares (a produção social do espaço para LEFÉBVRE, 1974, ou SANTOS, 2001), como se estabelecem suas relações de significação, suas contradições. No caso do lixo, a questão não é onde se deve jogar o lixo, mas que lixo é esse que foi produzido, com qual finalidade, com quais conseqüências, por quem, etc, evidenciando as relações de produção e consumo com as práticas que interligam ambientes invisíveis aos usuários.

É comum perceber espaços como praças e até mesmo parques, que são espaços destinados ao lazer e fruição cotidianos da população, que não são nem percebidos por ela, são meros espaços de passagem, muitas vezes mal conservados e que acabam sendo apropriados para outros usos, como lugares de prostituição e uso de drogas. Lugares que poderiam ser locais de sociabilidade, de usos para lazer, acabam se tornando locais de repulsa pela população, e de desvalorização dos lugares que pertencem ao seu cotidiano. Identificar e entender os fatores que levam à desvalorização, ao mal uso desses espaços pode ser um primeiro passo para que se consiga pensar em ações para a Educação Ambiental.

É essa a valorização, que parte da afetividade, que se defende para uma maior sensibilização das pessoas à Educação Ambiental. Acredita-se que se as pessoas não são capazes de conservar e valorizar os ambientes pertencentes ao seu cotidiano, percebendo de modo solidário as contradições e as interligações invisíveis, como se sugere acima, e que abrigam desigualdades injustas, elas não o farão em nenhum outro lugar, verdadeiramente.

Está claro, portanto, que a consciência de valorização e conservação dos lugares não se ensina com apostilas e falas superficiais. Interpretar os ambientes e suas paisagens não se aprende em nenhum manual, é vivência e conhecimento que se constrói a partir dessas experiências. Nas entrevistas que Hintze fez com as operadoras de Ecoturismo sobre a Educação Ambiental, percebe-se claramente que nenhuma delas sabe como implantar a atividade sem que isso cause prejuízo ao negócio. Muitas delas oferecem material informativo sobre os lugares, contratam guias locais, mas nenhuma delas julga o programa eficaz, e realmente não é tarefa fácil, pois não dependem apenas da criatividade e eficiência das operadoras e dos guias, que já ope- 
ram em limites bastante estreitos, mas em grande parte à sensibilidade e predisposição dos turistas, no contexto discutido acima.

A base na qual as atividades de Ecoturismo estão alicerçadas, através de programas e projetos de desenvolvimento, são razoáveis, há de fato uma preocupação com a qualidade da oferta, porém, a prática observada não condiz com o que está no papel. Segundo o Projeto OCE (SALVATI. s/d) , os princípios do Ecoturismo são:

- $\quad$ conservação e uso sustentável dos recursos naturais e culturais;

- $\quad$ informação e interpretação ambiental;

- $\quad$ é um negócio e deve gerar recursos;

- $\quad$ deve reversão dos benefícios para a comunidade local e para a conservação dos recursos naturais e culturais;

- deve ter envolvimento da comunidade local.

Os critérios do Ecoturismo (SALVATI. s/d) são:

- $\quad$ manejo e administração verde do empreendimento;

- associações e parcerias entre os setores governamentais e nãogovernamentais locais, regionais e nacionais;

- $\quad$ Educação Ambiental para o turista e para a comunidade local;

- $\quad$ guias conscientes, interessados e responsáveis;

- $\quad$ planejamento integrado, com preferência à regionalização;

- $\quad$ promoção de experiências únicas e inesquecíveis em um destino exótico;

- $\quad$ monitoramento e avaliação constantes;

- $\quad$ turismo de baixo impacto;

- $\quad$ código de ética para o mercado de Ecoturismo.

Como se percebe, a atividade carece de conceituação, embora se mostre preocupada com as diversas variáveis do Ecoturismo, enquanto atividade de mercado e de interferência nos ambientes. De fato, não chega a construir uma teoria, já que seu vínculo imediato com a produção a impede de buscar entender como se dá essa produção, quais suas implicações. O como fazer, os métodos de aplicação e desenvolvimento não podem assim ser explicitados nem submetidos a um pensamento crítico. Não indicam um caminho, e pelo que consta, não há interesse dos envolvidos em sua prática, em encontrar esse caminho. Além disso, existem itens extremamente vagos e 
superficiais, como por exemplo, a "promoção de experiências únicas e inesquecíveis em um destino exótico", ou ainda contraditórios entre os princípios e os critérios, como ser um "negócio que deve gerar lucros" e ao mesmo tempo" um turismo de baixo impacto" em "ambientes exóticos". Como fazer isso? Também quando cita as condições dos guias, o que se presencia é seu oposto, não há investimento adequado em capacitação, além de sua má remuneração. Observações em alguns destinos ecoturísticos indicam a baixa participação, quando há alguma, dos guias e população local nos negócios, reduzidos à mão de obra pouco qualificada.

Distribuir panfletos ou qualquer outro material informativo aos turistas não é Educação Ambiental, é apenas informação, por vezes discutível. Contratar um guia local com falas decoradas também não é Educação Ambiental, é superficialidade. Esse modelo de Educação Ambiental desenvolvido pelas empresas de Ecoturismo, através de material informativo e guias pouco habilitados, sem criatividade, não tem surtido o efeito necessário, pelo contrário, por vezes, cria-se repulsa, como observado no caso relatado como exemplo neste trabalho. Não é dessa forma que um ambiente é interpretado. Deve-se ainda observar que esse projeto é também pouco respeitoso com o guia local, já que não visa seu desenvolvimento e autonomia, mas ao contrário, o coloca como elo em uma cadeia de negócios à qual, de fato, não interessa seu crescimento, reforçando o caráter padronizado e superficial resultante dessa estratégia de negócios.

No caso mencionado no início, a falta de interesse dos turistas pelas explicações e pelas atividades monitoradas não causou preocupação ao guia (e acredita-se que nem ao proprietário da pousada). Diante desse fato, é possível afirmar que as atividades controladas, pelo menos da forma que vem sendo desenvolvida, não causam interesses em parte significativa das pessoas que procuram por destinos de natureza. A questão então seria verificar se esse desinteresse também pode indicar um caminho.

O desinteresse é pela forma programada de conduzir atividades, mas há muito interesse em se conhecer os atrativos, em vivenciar os locais, em conversar com os moradores locais (como observado também em Itararé). Quanto mais o turista conseguir vivenciar os lugares, estabelecendo relações de afetividade (que decorrem de experiências e histórias de vida de cada pessoa, e, portanto, é diferente para cada um), mais ele se interessará pelo lugar, por suas histórias e assim também o desejo de que aquele lugar seja conservado. Porém, isso não mudará, mesmo que se aprimore um pouco a situação, o fato de que se trata de uma atividade ocasional que não será suficiente para produzir um resultado em relação a uma condição de estranhamento. $O$ que permite indicar mais uma dimensão essencial desse impasse. A "consciência ambiental" não existe nem é possível no âmbito do indivíduo, mas boa parte dos programas ambientais isola o indivíduo como foco da transformação desejada, como se a mudança de comportamento fosse o "fazer a sua parte".

Essa fragilidade já não está somente no turismo, mas na própria forma adoci- 
cada e superficial de parte das proposições no âmbito da Educação Ambiental. A recusa de entender e inventar uma prática coletiva, substituindo- a por uma condição exacerbadamente individualista, além de contraditória em relação a um fato que em todos os sentidos é público, é insuficiente para ultrapassar o nível comportamental mais superficial. Além disso, o espaço social não é harmônico e ignora-se deliberadamente isso, e as dimensões afetivas implicadas.

Pode-se saber tudo sobre a natureza, mas isso não é suficiente para preservá-la. Para preservá-la, deve-se ter com ela uma relação afetiva, de amor, que gere o desejo de que ela continue existindo. O amor é que dá um sentido maior às coisas. Mas isso é algo muito delicado de se introduzir nesse mundo objetivo, ou melhor, pretensiosamente objetivo (NEIMAN, 2002, p. 173-174).

A Educação Ambiental através do Ecoturismo não deve ser uma atividade isolada de todas as outras, ela deve ser complemento, deve ser um meio de conscientização ambiental, deve ser uma possibilidade e exercício de interpretação e valorização dos lugares, que parte primeiramente da valorizar os lugares do cotidiano. Isolada, essa Educação Ambiental pelo Ecoturismo é apenas discurso e ferramenta de marketing.

Outra questão que precisa ser pensada é sobre esse modelo de (eco) turismo que vem sendo desenvolvido, que, se por um lado, causa um descontentamento para alguns que acreditam que vem sendo banalizada em sua oferta, para outros é considerada muito eficiente, portanto, que atende a uma necessidade. Quais são e de quem são essas necessidades? (SANDEVILLE JR; SUGUIMOTO, 2008, p. 09).

Partindo das premissas apresentadas, pode-se afirmar que para as empresas de Ecoturismo, esse modelo criticado pelos autores, é, na verdade, altamente interessante, suprindo suas necessidades. Atende também às necessidades de turistas, pois é comprovado o aumento da demanda para o segmento, que talvez se ausente no desejo vago de contato com a natureza, que pode ser satisfeito por modelos de Ecoturismo, que são apenas uma possibilidade de consumo de paisagens.

Como ferramenta de Educação Ambiental, o modelo apresentado é ineficaz, ou seja, não atende a real necessidade de conscientização ambiental que ecoe em atitudes de conservação. As duas atividades, turismo e Educação Ambiental parecem, na verdade, andar na contramão. Enquanto o turismo é uma atividade de mercado que instiga o consumo, tentando amenizar seus impactos (sociais e ambientais) através de discursos ambientalistas superficiais, a Educação Ambiental necessita de outras 
ferramentas para acontecer. No entanto, o (eco) turismo precisa dessa Educação Ambiental para viabilizar a visitação a locais ambientalmente frágeis, iniciando um ciclo cuja reprodução é sua fragilidade.

O turismo no quadro atual, não terá como escapar da própria armadilha, porque pretende trabalhar um sintoma, sem dar-se conta que é parte deste sintoma. A questão se leva para além do problema do turismo e reduzi-la ao seu campo, sobretudo ao momento de uma relação comercial em torno do lazer, continuará evidenciando de um modo vago as contradições para os usuários, favorecendo seu breve esgotamento.

A forma como as duas atividades foram conectadas não tem se mostrado eficaz, nem por parte dos turistas que muitas vezes não se interessam pelos métodos de Educação Ambiental, nem pelos empresários que não sabem aliar educação ao turismo e não estão verdadeiramente dispostos a investirem nela. É necessário repensar se o turismo pode ser uma atividade menos impactante aos ambientes em relação a outras atividades econômicas e se pode, de fato, redundar em benefício social nos locais de visitação; se o Ecoturismo é realmente um segmento que contribui na conservação dos lugares ou se incentiva ainda mais o seu desgaste, inclusive sociocultural, através do consumo.

É necessário também avaliar os métodos para Educação Ambiental. As emergências são visíveis, mas enquanto as questões subjetivas não forem levadas em consideração, ou seja, a afetividade, as experiências e vivências com os lugares e a valorização dos mesmos, as contradições que constroem essas experiências, será muito difícil alcançar uma consciência ambiental que faça diferença.

Com o incentivo cada vez maior ao consumo exacerbado, ao turismo que gera divisas imensuráveis, ao incremento da cadeia produtiva do turismo e a grande importância aos status de praticar turismo, é recomendado que se pense se o Ecoturismo não é, na verdade, uma forma de (des)Educação Ambiental. Através do aperfeiçoamento tecnológico que torna possível levar as pessoas a qualquer parte do planeta, e com os turistas cada vez mais afoitos pela descoberta e consumo de novos lugares, é possível pensar que o turismo ou o Ecoturismo, torna-se, na verdade, o grande incentivador da devastação cultural e ambiental dos lugares, tendo a educação como ferramenta de marketing e não como forma de conservação.

O discurso de sustentabilidade do turismo e com maior ênfase do Ecoturismo é, na realidade, um discurso fantasioso, que não engana os turistas, pois o grande atrativo são os lugares em si, a expectativa em se conhecer novos lugares, em se consumir suas paisagens, a Educação Ambiental não é atrativo. O desafio é encontrar uma forma que possibilite aos turistas interpretarem os ambientes, estabelecerem vínculos que possibilitem a afetividade e sua valorização em quadros sociais, os quais, entretanto, devem permanecer invisíveis ou tronarem-se cenários. 


\section{Referências Bibliográficas}

ABETA. Associação Brasileira das Empresas de Ecoturismo e Turismo de Aventura. Disponível em: http://www.abeta.com.br. Acessado em 16/09/2009.

BRASIL. Ministério da Indústria, Comércio e Turismo. Ministério do Meio Ambiente. Diretrizes para uma política nacional de ecoturismo. Brasília, DF: EMBRATUR/ IBAMA, 1994.

HINTZE, H.C. Ecoturismo na cultura de consumo: possibilidade de Educação Ambiental ou espetáculo? Dissertação de Mestrado: ESALQ-usp, 2008.

LEFÉBVRE, H. La Production de l'espace. Paris: Éditions Anthropos, 1974.

NEIMAN, Z. O cerrado como instrumento para Educação Ambiental em atividades de Ecoturismo. In: NEIMAN, Z. (org) Meio ambiente , Educação e Ecoturismo. Barueri, SP: Manole, 2002.

. A Educação Ambiental através do contato dirigido com a natureza. Tese de Doutorado: Instituto de Psicologia - USP, 2007.

SALVATI, S.S. O Ecoturismo: conceitos e princípios. Disponível em http:// www.ambientebrasil.com.br/composer.php3?base=./Ecoturismo/ index.html\&conteudo=./Ecoturismo/artigos/conceitos.html, acessado em 01/10/2009.

SANDEVILLE JR., E.; SUGUIMOTO, F.T. A natureza do Ecoturismo. Artigo apresentado no V Seminário de Turismo do Mercosul, Caxias do Sul, 2008.

SANTOS, M. A natureza do espaço. Razão e Emoção. São Paulo: Edusp, 2001.

SUGUIMOTO, F.T. Paisagens do Médio Tietê: formas de usos e apropriação de suas águas para lazer. Dissertação de Mestrado: FAU USP, 2007.

Turismo de Aventura e Ecoturismo estão em crescimento no Brasil. Notícia publicada em 12/08/2009, disponível em http://www.viagembrasil.tur.br, acessado em 04/09/2009.

URRY, J. O olhar do turista. São Paulo: Studio Nobel: Sesc, 2001. 
NOTAS:

${ }^{1}$ Foram visitados empreendimentos de ecoturismo nas cidades de Atibaia, Itu, Brotas, Lupércio, Cornélio Procópio e Ubatuba.

${ }^{2}$ Não foi autorizada a divulgação do nome do empreendimento por seu proprietário.

${ }^{3}$ Turismo de Aventura e Ecoturismo estão em crescimento no Brasil. Notícia publicada em 12/08/2009, disponível em http://www.viagembrasil.tur.br.

${ }^{4}$ Idem

${ }^{5}$ Disponível em http://www.abeta.com.br

${ }^{6}$ Segundo a lei $n^{\circ}$ 9795, de 27/04/199, elaborada pelo Programa Nacional de Educação Ambiental, "entende-se por educação ambiental não-formal as ações e práticas educativas voltadas à sensibilização da coletividade sobre as questões ambientais e à sua organização e participação na defesa da qualidade do meio ambiente".

Euler Sandeville Júnior: Faculdade de Arquitetura e Urbanismo - Universidade de São Paulo (FAU-USP), e Programa de Pós-Graduação em Ciência Ambiental (PROCAM-USP).

Página pessoal: http://paisagemvivenciada.wordpress.com

Link para o currículo Lattes: http://lattes.cnpq.br/0285344763071129

Flávia Tiemi Suguimoto: Faculdade de Arquitetura e Urbanismo - Universidade de São Paulo (FAU-USP).

Email: flatiemi@terra.com.br

Link para o currículo Lattes: http://lattes.cnpq.br/3325611126601865

Data de submissão: 24 de outubro de 2009.

Data do aceite: 12 de dezembro de 2009. 